\title{
Evaluating Usability of E-Learning Systems in Universities
}

\author{
Nicholas Kipkurui Kiget \\ Department of Computer Science \\ Masinde Muliro University of \\ Science and Technology \\ Kakamega, Kenya
}

\author{
Professor G. Wanyembi, \\ Department of Information \\ Technology \\ Mt. Kenya University \\ Thika, Kenya
}

\author{
Anselemo Ikoha Peters \\ School of Computing and \\ Informatics \\ Kibabii University College \\ Bungoma, Kenya
}

\begin{abstract}
The use of e-learning systems has increased significantly in the recent times. E-learning systems are supplementing teaching and learning in universities globally. Kenyan universities have adopted e-learning technologies as means for delivering course content. However despite adoption of these systems, there are considerable challenges facing the usability of the systems. Lecturers and students have different perceptions in regard to the usability of e-learning systems. The aim of this study was to evaluate usability attributes that affect elearning systems in Kenyan universities. The study had two fold objectives; determining status of e-learning platforms and evaluating usability issues affecting e-learning adoption in Kenyan universities. The research took a case study of one of the public universities which has implemented Moodle e-learning system. The usability attributes evaluated were user-friendliness, learnability, technological infrastructure and policy. The research made recommendations which could help universities accelerate the adoption of e-learning systems.
\end{abstract}

Keywords-e-learning; moodle; usability; learnability

\section{INTRODUCTION}

E-learning systems are becoming accepted tools for teaching and learning. The e-learning systems provide a platform for using computers to improve education. According to [1], computers have become useful not only in corporate world but also in Education.

Popularity of e-learning systems is attributed to their key benefits. When applied correctly, e-learning systems can have the following benefits; reduced teaching and learning costs, reduced teaching and learning time, more effective learning / better lecturer productivity, more consistent learning, flexible delivery / distance delivery, measurable learning, recognition of prior learning and multi-cultural learning. The value of ELearning is to fully enable "learning anywhere at any time" by providing an array of resources, opportunities for active participation, mastering content and self learning [2].

As noted by Nielsen [3], inadequately equipped e-learning systems can result in frustration, anxiety, confusion, and reduce learners' interest. Miller [4], states that poor usability is a major contributor to lack of adoption of most e-learning systems. Usability of e-learning systems influence the way learners evaluate their learning experience, if usability of elearning system is bad, learners fail in their attempt to use the system. These factors hinder the usability of e-learning systems adopted in an institution of higher learning.

\section{CONCEPTUAL FRAMEWORK}

The conceptual framework in fig 1 shows the relationship linking the usability issues and the e-learning platforms; the usability issues that affect an e-learning platform are user friendliness, user satisfaction, learnability and errors [5]. The contravening factors are institutional strategies and policies, cultures and legal issues, demographic factors and technological infrastructure.

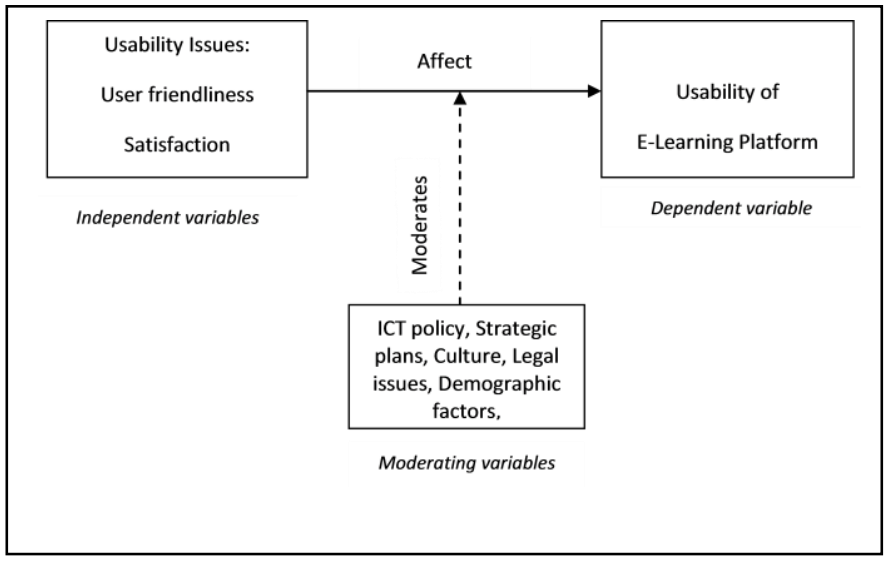

Fig.1. Conceptual framework

Source: Author (2014)

\section{HYPOTHESIS OF THE STUDY}

The following hypotheses were tested:

$\mathrm{H}_{01}$ : There is statistically no significant difference between the learnability and the usability of an e-learning system $\mathrm{H}_{02}$ : There is no statistically significant difference between the user-friendliness and the usability of an e-learning system $\mathrm{H}_{03}$ : There is no statistically significant difference between the usability policy and the usability of an e-learning system $\mathrm{H}_{04}$ : There is no statistically significant difference between the infrastructure and the usability of an e-learning system

\section{REVIEW OF RELATED LITERATURE}

E-learning systems, also called virtual learning environments (VLE's), are systems that use modern 
information and communication technology to aid education and training efforts [6]. A purpose of an e-learning system is to distribute the learning materials to the users. It enables instructors and learners to post content, participate in discussions, maintain a grade book, keep a roster, track participation, and generally engage in and manage learning activities in an online environment [7].

Learning Management Systems (LMS) fall in the category of technology delivered e-learning. It is used to support teaching and learning. LMS is the backbone of e-learning, which is a software system integrating web-based training, classroom delivered courses, online courses and human resources system as stated by [8].

The role of Learning Management System (LMS) is to deliver e-learning courses in a self paced approach. Through LMS lecturers are able to publish courses in an online catalog and also be able to assign online courses to the learners who then $\log$ in to the LMS using an internet browser and start the courses. LMS will then track the learners' activities and provide upto date reports for each course and each learner. Common LMS are Moodle, WebCT, Blackboard, eleap and desire2learn. This study targeted the users of Moodle elearning system.

\section{A. The need to evaluate e-learning system}

Evaluation is a course of action for determining the value and effectiveness of a learning system with benefits such as error correction, establishing the users' point of view and reducing unsupportable design issues in a system [9]. Shepherd [10] in his article, states that there are four reasons for evaluating e-learning system; validating training as business tool, justifying costs incurred in training, help improve design of training, and to help in selecting training methods. In the context of this study, the evaluation of the elearning system is to help enhance the design of the training and the design of the e-learning system.

\section{B. Usability of E-learning Systems}

According to International Organization for Standardization (ISO) 9241 [11], usability is defined as the degree to which a particular product is used by particular users to accomplish specific goal with efficiency, effectiveness and satisfaction in a precise standpoint used. Majority of the past studies on the usability of E-learning systems have been on exploring the usability of interface of E-learning systems and the links between usability features and the E-learning success.

Usability has been defined differently as specified in components that are more specific i.e. learnability, memorability, errors and efficiency [12]. Nielsen [3] gives attention to expert users when talking about efficiency though learnability is directly related to efficiency. Memorability mostly relates to casual users and errors deal with those errors not covered by efficiency, which have more disastrous results. A comparable definition is given by Shneiderman[13]; Shneiderman while defining usability of e-learning system looks at it as five measurable human factors central to evaluation of human factors goals; speed of performance, time to learn, retention over time, rate of errors by users and subjective satisfaction. Dix [14] defines concepts entailing system usability; learnability, flexibility and robustness signifying that those concepts are on the similar abstraction level.

\section{User-Based Evaluation of usability of e-learnig systems}

User-based evaluation presently provides complete form of evaluation, since it assesses usability by picking samples of real users. A suitable technique used in the research was the system inquiry in which users are asked to give their opinions or views on the way they perceive the system after using for some time.

\section{METHODOLOGY}

The research used case study approach which is one of the most widely used qualitative research method in information systems research [15], owing to its ability to understand the interaction between information technology and organizational contexts in a thorough manner. The population was drawn from students and lecturers using learning management system (Moodle). A sample of 20 lecturers and 30 students was used for the study. The study used questionnaires and interviews to collect the information from the respondents. Questionnaires from twenty five (25) students and fifteen (15) lecturers were dully filled, returned and used for analysis. This represented a response rate of $83 \%$ and $75 \%$ respectively.

\section{FINDINGS AND DISCUSSION}

\section{A. Gender Distribution of the Respondents}

Table I shows the gender disparity of the respondents. From the results, it is evident that $70.0 \%$ were male while $30 \%$ were female respondents. This shows that there are few female participants using the e-learning system. Among the lecturers, $73.3 \%$ were male while $26.7 \%$ were female. As for the students $68.0 \%$ were male while $32 \%$ were female.

TABLE I. GENDER DISTRIBUTION

\begin{tabular}{|c|c|c|c|c|c|}
\hline \multirow{2}{*}{\multicolumn{2}{|c|}{ Category }} & & \multicolumn{2}{|c|}{ Gender } & \multirow{3}{*}{$\begin{array}{r}\text { Total } \\
15 \\
\end{array}$} \\
\hline & & & \multirow{2}{*}{$\begin{array}{r}\text { Male } \\
11\end{array}$} & \multirow{2}{*}{$\begin{array}{r}\text { Female } \\
4\end{array}$} & \\
\hline 1 & Lecturers & Frequency & & & \\
\hline & & $\%$ & $73.3 \%$ & $26.7 \%$ & $100.0 \%$ \\
\hline \multirow[t]{2}{*}{2} & Students & Frequency & 17 & 8 & 25 \\
\hline & & $\%$ & $68.0 \%$ & $32.0 \%$ & $100.0 \%$ \\
\hline \multicolumn{2}{|c|}{ Total } & Frequency & 28 & 12 & 40 \\
\hline & & $\%$ & $70.0 \%$ & $30.0 \%$ & $100.0 \%$ \\
\hline
\end{tabular}

B. Level of Education and Category of Lecturers

Table II shows staff category and level of education of the lecturer respondents. The most common educational qualification of the respondents was the Masters, with a total of 10 representing $66.67 \%$ of the lecturers; followed by degree holders representing $13.3 \%$ while the least was the Doctorate representing $13.33 \%$. On the staff category most of the respondents were lecturers (7) representing $46.67 \%$ followed by Senior Lecturers and Assistant Lecturers each 3 representing 20\%, the least was Graduate Assistant / Tutorial Fellow representing $13.33 \%$ 
TABLE II. LEVEL OF EDUCATION AND STAFF CATEGORY

\begin{tabular}{|l|l|l|r|r|r|r|}
\hline & & \multicolumn{5}{|c|}{ Staff Category } \\
\hline & & $\begin{array}{l}\text { Graduate } \\
\text { Assistant / } \\
\text { Tutorial } \\
\text { Fellow }\end{array}$ & $\begin{array}{l}\text { Assistant } \\
\text { Lecturer }\end{array}$ & Lecturer & $\begin{array}{l}\text { Senior } \\
\text { Lecturer }\end{array}$ & Total \\
\hline $\begin{array}{l}\text { Degre } \\
\text { e }\end{array}$ & Count & 2 & 1 & 0 & 0 & 3 \\
\hline & $\%$ & 13.33 & 6.67 & 0 & 0 & 20 \\
\hline $\begin{array}{l}\text { Maste } \\
\text { rs }\end{array}$ & Count & 0 & 2 & 6 & 2 & 10 \\
\hline & $\%$ & 0.00 & 13.33 & 40.00 & 13.33 & 66.7 \\
\hline PHD & Count & 0 & 0 & 1 & 1 & 2 \\
\hline & $\%$ & 0 & 0.00 & 6.67 & 6.67 & 13.3 \\
\hline & Count & 2 & 3 & 7 & 3 & 15 \\
\hline & $\%$ & 13.33 & 20 & 46.67 & 20 & 100 \\
\hline
\end{tabular}

C. Experience of the Respondents with E-learning System

On the use of e-learning systems, all the respondents answered on affirmative as shown in table III. This means that all the respondents have an experience with e-learning systems. From the results, uploading, assignments, quiz and forum are the most frequently used modules recording $97.5 \%$, $100 \%, 65 \%$ and $95 \%$ respectively. The least used modules are journal, chats, workshop and choice at $32.5 \%, 15 \%, 32.5 \%$ and $42.5 \%$ of the respondents respectively.

TABLE III. E-LEARNING SYSTEMS USED

\begin{tabular}{|l|c|c|}
\hline E-learning System & Yes & No \\
\hline Wiki & $57 \%$ & $43 \%$ \\
\hline Moodle & $100 \%$ & $0 \%$ \\
\hline WebCT & $5 \%$ & $95 \%$ \\
\hline Blackboard & $5 \%$ & $95 \%$ \\
\hline Sakai & $0 \%$ & $100 \%$ \\
\hline
\end{tabular}

\section{Factors hindering implementation of e-learning systems}

As shown in table IV, $97.5 \%$ of the respondents agreed that lack of equipment (computers) hinders e-learning implementation, $85 \%$ of them didn't agree with the course quality concerns as a factor. $95 \%$ of the respondents agreed on the factor of access speeds while $57.5 \%$ did not think that lack of skills was a major contributing factor in hindering elearning systems. All respondents (100\%) did not agree to the following factors; lack of interest, not aware of its availability, legal concerns, plagiarism and course not suited to be implemented on the e-learning platform. $32.5 \%$ of the respondents agreed that institutional traditional culture and lack of motivation are hindering implementation of e-learning while $37.5 \%$ of them agree that policy is also affecting its implementation. A considerable number $42.5 \%$ also thought that having no usability policy in place was also affecting use of e-learning system.

TABLE IV. FACTORS HINDERING E-LEARNING

\begin{tabular}{|l|c|c|}
\hline Factor & Yes & No \\
\hline
\end{tabular}

\begin{tabular}{|l|c|c|}
\hline Lack of Equipment (Computers) & $97.5 \%$ & $2.5 \%$ \\
\hline Course quality concerns & $15 \%$ & $85 \%$ \\
\hline Access Speeds & $95 \%$ & $5 \%$ \\
\hline Lack of Skills & $42.5 \%$ & $57.5 \%$ \\
\hline Lack of Interest & $0 \%$ & $100 \%$ \\
\hline Not aware of its availability & $0 \%$ & $100 \%$ \\
\hline University Traditional Culture & $32.5 \%$ & $67.5 \%$ \\
\hline Lack of Motivation & $32.5 \%$ & $67.5 \%$ \\
\hline Lack of policy & $37.5 \%$ & $62.5 \%$ \\
\hline Legal Concerns & $0 \%$ & $100 \%$ \\
\hline Course not suited for E-learning & $0 \%$ & $100 \%$ \\
\hline Plagiarism concerns & $0 \%$ & $100 \%$ \\
\hline
\end{tabular}

E. Moodle modules used by respondents

Table $\mathrm{V}$ shows that uploading, assignments, quiz and forum are the most frequently used modules recording $97.5 \%$, $100 \%, 65 \%$ and $95 \%$ respectively. The least used modules are journal, chats, workshop and choice at $32.5 \%, 15 \%, 32.5 \%$ and $42.5 \%$ of the respondents respectively.

TABLE V. MOODLE MODULES USED

\begin{tabular}{|l|c|c|}
\hline Modules used & Yes & No \\
\hline Uploading & $97.5 \%$ & $2.5 \%$ \\
\hline Assignment & $100 \%$ & $0 \%$ \\
\hline Quiz & $65 \%$ & $35 \%$ \\
\hline Journal & $32.5 \%$ & $67.5 \%$ \\
\hline Chats & $15 \%$ & $85 \%$ \\
\hline Workshop & $32.5 \%$ & $67.5 \%$ \\
\hline Forum & $95 \%$ & $5 \%$ \\
\hline Choice & $42.5 \%$ & $57.5 \%$ \\
\hline Any other & - & - \\
\hline
\end{tabular}

\section{F. Hypotheses tested}

a) Hypothesis 1

There is no statistically significant difference between the learnability and the usability of an e-learning system.

\section{Null Hypothesis}

Learnability factors do not affect the usability of e-learning system.

\section{Alternative Hypothesis}

Learnability factors affect the usability of e-learning system.

To determine whether there was or no statistical significant difference between learnability and the usability of an elearning system, a linear regression was used. Usability factor was tested with the following learnability factors: "Learning to use LMS system is easy for me", "Exploring new modules by trial and error is easy", "Easy to be skilful with the LMS" and "Easy to upload and download using LMS". Table VI shows 
linear regression results on learnability issues affecting the usability of e-learning system. From the results, the learnability factors significant are "Learning to use e-learning system is easy" with $\mathrm{p}=0.044$, "exploring new modules by trial and error is easy", with $\mathrm{p}=0.701$ and "Easy to be skillful" being strongly significant with $\mathrm{p}=0.009$ while "Easy to Upload / Download" has significance of $\mathrm{p}=0.346$

TABLE VI. SINIFICANCE OF LEARNABILITY FACTORS

\begin{tabular}{|l|l|r|}
\hline Model & & \multicolumn{1}{|c|}{ Sig. } \\
\hline & Learning to use is easy & 0.044 \\
\hline & Exploring new modules by trial and error easy & 0.701 \\
\hline & Easy to be skillful & 0.009 \\
\hline & Easy to Upload / Download & 0.346 \\
\hline
\end{tabular}

Thus the Null hypothesis is disproved and the alternative accepted that there is a significant difference between the learnability factors and usability of the e-learning system. This means that the learnability factors affect the usability of elearning system considerably. If a system is not easy to learn then it affects its usability. This is in agreement with Ghaoui [5] who while surveying usability issues affecting e-learning systems stated that learnability was one of them. Higher learnability therefore relates to greater usability.

\section{b) Hypothesis 2}

There is no statistically significant difference between the user-friendliness and the usability of an e-learning system.

\section{Null Hypothesis}

User-friendliness factors do not affect the usability of elearning system.

\section{Alternative Hypothesis}

User-friendliness factors affect the usability of e-learning system.

To determine the significant difference between the userfriendliness and usability of e-learning system, a linear regression was done on the following variables: usability on one hand and user-friendliness factors on the other hand. The user-friendliness factors identified were "Accessing menus and commands is easy for me" and "My interaction with LMS is clear and understandable". Table VII shows the results of the correlations.

TABLE VII. ANALYSIS OF USER-FRIENDLINESS FACTORS

\begin{tabular}{|l|l|c|}
\hline Model & & Sig. \\
\hline & Accessing Menus and Commands easy & 0.007 \\
\hline & Interaction with LMS clear & 0.002 \\
\hline
\end{tabular}

From the results, "Accessing Menus and Commands easy" is strongly significant with $\mathrm{p}=0.007$, while "Interaction with LMS clear" is also strongly significant with $\mathrm{p}=0.002$. According to the Pearson Correlation the user-friendliness factors affects the usability of e-learning system. Therefore this negates the hypothesis hence there is a significant difference between the user-friendliness and usability of e- learning system. This therefore means that user-friendliness affects the usability of e-learning systems.

The results conforms with Yildrin [8]; according to Yildrin [8], there are four key issues to successful LMS; general features and functionality / user-friendliness, content/ID, Support tools and management and technical; infrastructure

\section{c) Hypothesis 3}

There is no statistically significant difference between the usability policy and the usability of an e-learning system.

\section{Null Hypothesis}

Usability policies do not affect the usability of e-learning system.

\section{Alternative Hypothesis}

Usability factors affect the usability of e-learning system.

To determine whether there was significant difference between the usability policy and usability of e-learning system, a linear regression analysis was carried out between the usability factor and need for a policy factor. Table VIII shows the results of the analysis.

TABLE VIII. USABILITY POLICY IN RELATION TO USABILITY FACTOR

\begin{tabular}{|l|l|r|}
\hline Model & & Sig. \\
\hline 1 & (Constant) & 0.000 \\
\hline & Usability Policy & 0.739 \\
\hline
\end{tabular}

With a significance of 0.739 as indicated in the linear regression analysis, the statistical significance difference between usability policy and usability of e-learning system is weak. This means that though the significance is weak, usability policy affects the usability of e-learning system. This seems to agree with Al Rawi [7] who indicated that lack of a policy framework on e-learning has hampered development of technology in institutions of education.

\section{d) Hypothesis 4}

There is no statistically significant difference between the infrastructure and the usability of an e-learning system.

\section{Null Hypothesis}

Technological infrastructural factors do not affect the usability of e-learning system.

\section{Alternative Hypothesis}

Technological infrastructural factors affect the usability of e-learning system.

To test the significance difference between the infrastructure and the usability of e-learning system, a linear regression was performed on usability factor and the infrastructural factors. The infrastructural factors identified were "There is need for more computers for e-learning use" and "I can access e-learning system while in LAN and while on a WAN (Through the web on the Internet)". Table IX shows the results of the analysis.

TABLE IX. INFRASTRUCTURAL FACTORS IN RELATION TO USABILITY FACTOR 


\begin{tabular}{|l|l|c|}
\hline \multicolumn{1}{|c|}{ Model } & & Sig. \\
\hline 1 & (Constant) & 0.001 \\
\hline & More Computers & 0.007 \\
\hline & Can be accessed on LAN and WAN & 0.006 \\
\hline
\end{tabular}

\section{CONCLUSION}

The aim of the research was to study the usability of elearning system being used in one of the public universities in Kenya. The factors of usability evaluated were learnability, user-friendliness, technological infrastructure, usability policy, culture and gender. The results from this study showed that a significant number of users agreed that learnability of elearning system was affecting its usability. The learnability factors tested were the ability of e-learning system to be learnt, exploring new modules by trial and error, ability to be skilful with an e-learning system and ability of users to upload and download using e-learning system. Generally most of the respondents agreed that learning e-learning and using elearning system was not easy.

This is in tandem with Dix [14] who noted that learnability affects usability of e-learning system. To enhance the adoption of e-learning systems, universities have to enhance the learnability of e-learning systems. Smulders [18], described usability of e-learning as a precursor of learnability.

The research also identified user-friendliness as a factor that affects usability of e-learning system. Majority of the responses agreed that e-learning system has to be user friendly for it to be usable. User-friendliness factors investigated were the ease to access menus and commands and clarity of interaction between the user and the e-learning system.

According to the findings universities need more computers and more training for both lecturers and students to enhance adoption of e-learning system. The e-learning system should also be accessible on a local area network and on a wide area network over internet.

\section{RECOMMENDATIONS}

Though $90 \%$ of the respondents agree that they have had training organised by the university, still $90 \%$ of them agree to the fact they still need more trainings / workshops on elearning system. The research therefore recommends more training / workshops are done to enhance learnability of elearning system.

Three modules of Moodle were frequently used according to the respondents. These were uploading / downloading, assignment and forum. It is recommended that the lecturers and students be trained and encouraged to use other modules which could enhance learning; these include chat, workshop, assignment and quiz. According to Moodle website www.moodle.com (2010), all the seven modules; uploading / downloading, forums, chats, quizzes, Assignments, grades and wikis makes e-learning process complete.

The research recommends enough computers be purchased by the universities for successful implementation of e-learning system. The e-learning system should be accessible both on Local Area Network (LAN) and on internet.
Lack of e-learning policy has affected the usability of elearning system. Newhouse [19], states that it's through elearning policy that students can know what the instructor expects from them. It is recommended that universities come up with e-learning policies such as usability policy to guide the learners, lecturers and management staff as they implement the systems. The policy will encourage professionalism in creating, uploading and sharing of digital content by the lecturers and learners.

\section{Suggestions For FurTher RESEARCH}

This research focused on Moodle as a Learning Management System that had been implemented by the university under the study. Comparative study is suggested to look at usability issues of other e-learning systems not covered by this research.

The study took a sample of students and lecturers from computer science department, a further study could be done to understand the perception of other lecturers and students in other departments and other universities on e-learning systems. Additionally, a comparative study on open source and proprietary e-learning systems is also suggested.

\section{REFERENCES}

[1] Sambrook, S., (2003), 'E-learning in Small Organizations', Education + Training, vol.45, no.8/9, pp. 506-516.

[2] Norman, V. (2007). Perspectives on blended learning in higher education. Journal of ELearning, January.

[3] Nielsen, J. (2005). Heuristic Evaluation. Retrieved 22/06/2014, from http://www.useit.com/papers/heuristic/

[4] Miller, M.J. (2005). Usability in E-learning. Retrieved 11/07/2014, from www.learningcircuits.org/2005/miller.htm

[5] Ghaoui, C. (2003). Usability Evaluation of Online Learning Programs. Information Sciences Publishing.

[6] Dowming (2008). What drives a successful e-Learning? An empirical investigation of the critical factors influencing learner satisfaction, Computers \& Education, Vol. 50 (4), pp 1183-1202.

[7] Al-Rawi, A. (2010). Using a learning management system to foster independent learning in an outcome-based university: A gulf perspective. Proceedings of Issues in Informing Science and Information Technology (pp. 73-87). Retrieved from http://iisit.org/Vol7/IISITv7p073-087Lansari733.pdf

[8] Yildirim and Temur, H., (2004), Handbook on LMS: Success factors in e-learning implementation. John Wile, Inc.

[9] A.M. Lund (2004): Measuring usability with the use questionnaire, http://www.stcsig.org/usability/newsletter/0110 measuring with use.htm, last accessed: 05/06/14

[10] Shepherd, C. (2002). In search of the perfect e-tutor. Accessed on 15/07/2014 from: http://www.fastrakconsulting.co.uk/tactix/Features/ perfect_etutor.htm

[11] ISO (1998) ISO 9241: Guidance on Usability Standards. [On-line]. Available: http://www.iso.org/iso/iso_catalogue/catalogue_ics /catalogue_detail_ics.htm?csnumber=16883\&ICS1=13\&ICS2=180\&IC S3

[12] Nielsen, J. (1993). Usability Engineering. New Jersey: Academic Press. Smulders, D. (2003). Designing for Learners, Designing for Users, eLearn Magazine, last accessed 08/07/2014, from Http://www.elearnmag.org/.

[13] Shneiderman, B. (2004). Designing the User Interface: Strategies for effective Human-Computer Interaction (3 ed.). Addison-Wesley.

[14] Dix, K.L. (2006). A longitudinal study examining the Impact of ICT adoption on students and teachers. Unpublished Doctoral Thesis. Flinders University: Adelaide, South Australia. 
[15] Yin R.K. (2003), Case study research - Design and Methods, $3^{\text {rd }}$ edition, thousand Oaks, Califonia-Sage Publication.

[16] Yildirim, S., Temur, N., Kocaman, A. and Goktas, Y. What makes a good LMS: An analytical approach to assessment of LMSs. In Proceedings of the Fifth International Conference on Information Technology Based Higher Education and Training. (Istanbul, Turkey, May 31-June 2, 2004), 125-130.
Gachenge, B. (2008). E-learning taking root in Educational Institutions. Date accessed 12/06/2014 from http://allafrica.com/stories /200807011188.html

[17] Smulders D. (2001). Web Course Usability. http://www.learningcircuits.org/2001/aug2001/elearn.html .

[18] Newhouse (2004), The Impact Of ICT On Learning And Teaching, A Literature Review, Western Australia Department Of Education. 